\title{
Designing Dispersion Flattened Photonic Crystal Fiber for Wideband Applications
}

\author{
${ }^{1}$ Kubra Bashir, ${ }^{2}$ Rabia Zaman, ${ }^{3}$ Irfan Ahmed, ${ }^{4}$ Muhammad Imran Aslam \\ 1,2 Department of Electrical Engineering, Institute of Business Management, Karachi Pakistan \\ ${ }^{3,4}$ Department of Electronic Engineering, NED University of Engineering and Technology, Karachi Pakistan
}

${ }^{1}$ kubra.bashir@iobm.edu.pk

2 rabia.zaman@iobm.edu.pk

\begin{abstract}
In this paper, we proposed a dispersion flattened photonic crystal fiber (PCF) for having very low dispersion for wide bandwidth as well as low confinement loss. The proposed fiber has been numerically analyzed for Silica core as well as Borosilicate crown glass core with square lattice air holes. In the proposed design we have used elliptical air holes in the inner ring whereas outer rings are circular. Finite Element Method based software tool is used to analyze the proposed design. This comparison of core materials deduces that Borosilicate crown glass PCF produces negative dispersion, making it a good candidate to be used as Dispersion Compensating Fiber (DCF), whereas Silica PCF provides nearly zero dispersion at wavelength range $1.35 \mu \mathrm{m}$ to $1.70 \mu \mathrm{m}$.
\end{abstract}

Keywords - Confinement Loss; Dispersion; Dispersion Compensating Fiber; Dispersion Flattened Fiber.

\section{INTRODUCTION}

In telecommunications, Optical fibers have made an influencing impact due to its high bandwidth, high speed data transmission, security and reliability over long distances as discussed in [1]. Further the advent of wavelength division multiplexing has made optical fibers stronger candidate to meet the demands of higher bandwidth as discussed in [2]. By virtue of low transmission loss the telecommunication applications of Silica-based optical fibers are focused in the wavelength range 1.2-1.6 $\mu \mathrm{m}$ as mentioned in [3].

PCF is one of the latest developments of this field. It includes three parts similar to the conventional fiber, where solid core consists of glass material, cladding and microscopic air holes as discussed in [4]. One of the strength of PCF is its design flexibility with desirable optical characteristics as mentioned by Partha Sona Maji [5]. By modifying the geometry of air holes, it can provide enormous propagation properties therefore, these fibers seems to be appropriate for compensating the dispersion of conventional fiber optic links as discussed in [6]. Through suitable selection of holes diameter, hole-hole spacing known as pitch constant $(\Lambda)$, number of rings $(\mathrm{Nr})$, and arrangement of air holes, several impressive properties like dispersion, confinement loss, effective area, non-linearity etc. can be controlled as examined in [7], [8].

In WDM optical communication system, larger bandwidth with flattened dispersion is one of the major issue as discussed in [9]. To achieve flattened dispersion many techniques have been used earlier such as by varying shape and diameter of air holes by filling air holes with different liquids and gases as mentioned in [10-13]. In the past researches, a hexagonal geometry with five number of rings by using Silica has been investigated by Jay Parakash and Md. Sabir in [14]. A square lattice PCF structure is investigated in [15] and [16]. Furthermore, few other researches on PCF adjustments in structural parameters with zero dispersion and dispersion shifted fibers are discussed in [17], [18].

Other researches like single mode PCF is required for longer transmission without interference using octagonal lattice is discussed in [19]. Several other geometries of PCF with higher nonlinearity are examined in [20-24]. Another reported research on low confinement loss by changing PCF structure is observed in [25].

In this work, we analyze a square lattice PCF structure with a new modified geometry using two inner elliptical and three outer circular air hole rings using both Silica and Borosilicate crown glass as their core materials and extracted optical properties like dispersion and confinement loss. The PCF designed in this work exhibit the flattened dispersion for the wavelengths of interest when Silica is used as the core material. The same fiber exhibit properties of dispersion compensating fiber when the core material is Borosilicate.

\section{DISPERSION IN PCF}

For a guided mode in a PCF, effective refractive index $\left(n_{\text {eff }}\right)$ of the mode can be obtained by calculating the Eigen value of Maxwell's equation. Typically the effective index is a complex number having both real and imaginary value and is given by [14].

$$
n_{\text {eff }}=\beta / k_{0}
$$


Here, $\beta$ is the propagation constant and $k_{0}$ is the free space wave number.

Dispersion is problematic in transmission capacity of the system. It is caused by the scattering of light waves, because of the difference either in constants of propagation or in material's refractive index. In optical communication system, control of chromatic dispersion is vital in PCFs and in fibers it can be calculated by using real part of $n_{\text {eff }}$ as observed in [26].

Where,

$$
D=-\frac{\lambda}{c} \frac{d^{2} \operatorname{Re}\left[n_{e f f}\right]}{d \lambda^{2}}
$$

$c$ is speed of light and $\lambda$ is wavelength of the light in fiber.

Confinement Loss is defined as the loss arising from the leaky nature of the guided modes due to non-perfect wave confinement in the PCF structure. |It is calculated by using imaginary part of $n_{e f f}$ as shown in [27].

$$
C L=8.686 \frac{2 \pi}{\lambda} \operatorname{Im}\left[n_{e f f}\right] \quad\left[\frac{d B}{m}\right]
$$

\section{PCF DESIGN}

The proposed PCF design consists of five rings of air holes (Nr) along with solid core. For the first two rings, air holes are made elliptical having major axis (a) of $0.4 \mu \mathrm{m}$ and minor axis (b) is of $0.1 \mu \mathrm{m}$, whereas for the outer three rings, air holes are of circular shape with the diameter (d) of $1.0 \mu \mathrm{m}$ and pitch $(\Lambda)$ is of $2.3 \mu \mathrm{m}$. The structure of lattice is selected as a square and perfectly matched layer (PML) is circular as shown in Figure 1. Two different core materials Silica and Borosilicate crown glass are chosen for the proposed geometry and the optimization is performed by using different geometric design approximations.

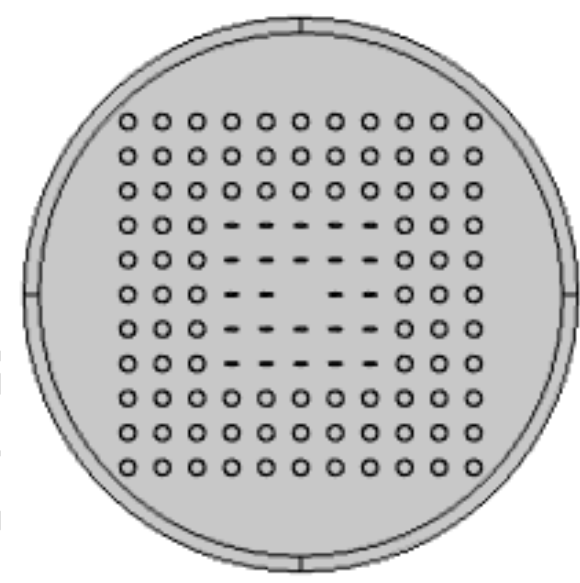

Fig. (1). Geometry of proposed PCF of square lattice with two inner elliptical rings with major axis $\mathrm{a}=0.4 \mu \mathrm{m}$, minor axis $\mathrm{b}=0.1 \mu \mathrm{m}$ and three outer circular rings with diameter $\mathrm{d}=1.0 \mu \mathrm{m}$ and pitch $\Lambda=2.3 \mu \mathrm{m}$

Figure 2 summarizes the steps involved in the designing and simulation of PCF. In this work, we used Finite Element
Method (FEM) based software package COMSOL Multiphysics to model the PCF and calculate effective refractive index.

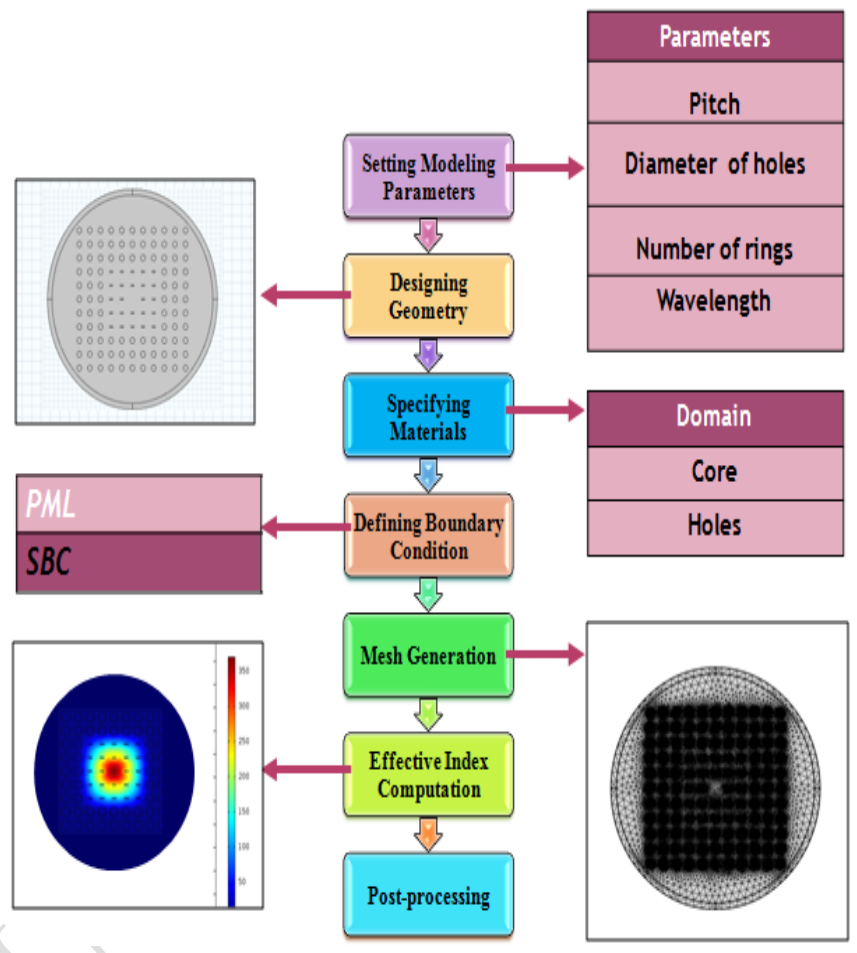

Fig. (2). Simulation flow diagram for proposed PCF Structure.

The first step of Figure 2 shows, the specification of the physical parameters such as pitch, diameter of holes, refractive indices (which is calculated by Sellmeier's equation) and wavelength of light are used. Second step is then designed in such a way that two inner elliptical air hole rings and three outer circular air hole rings arranged in a square lattice. Next, core and hole domains are linked to appropriate materials, after that boundary condition perfectly matched layer (PML) is defined. PML is used as it represents the absorbing layer that is used to absorb electromagnetic waves without reflecting back into modeling space as discussed by Jean-Pierre Beranger in [28]. The next one is meshing by sub-dividing the structure into finite size elements to compute effective refractive indices. The real part of effective refractive index used to calculate dispersion whereas the imaginary part to compute confinement loss. And finally post-processing is done and graphs are plotted with the help of MATLAB software.

For simulation purposes the refractive index of Silica and Borosilicate is represented using their respective Sellmeier's equations. As mentioned in [29] the refractive index of Silica is given by its Sellmeier's equations as.

$n(\lambda)=\mathrm{A}_{0}-\mathrm{A}_{1} \lambda^{2}-\mathrm{A}_{2} \lambda^{4}+\frac{\mathrm{A} 3}{C}-\frac{\mathrm{A} 4}{C^{2}}+\frac{\mathrm{A} 5}{C^{3}}$

Where

$\mathrm{A}_{0}=1.4508554$ 
$\mathrm{A}_{1}=0.0031268$

$\mathrm{A} 2=0.0000381$

$\mathrm{A} 3=0.0030270$

$\mathrm{A} 4=0.0000779$

$\mathrm{A} 5=0.0000018$

$\mathrm{C}=\lambda^{2}-0.035$

Further, the Sellmeier's equation for Borosilicate crown glass material is given by [30]-[31].

$n^{2}(\lambda)=1+\frac{\mathrm{B} 0 \lambda^{2}}{\left(\lambda^{2}-\mathrm{B} 1\right)}+\frac{\mathrm{B} 2 \lambda^{2}}{\left(\lambda^{2}-\mathrm{B} 3\right)}+\frac{\mathrm{B} 4 \lambda^{2}}{\left(\lambda^{2}-\mathrm{B} 5\right)}$

Where

$\mathrm{B} 0=1.03961212$

$\mathrm{B}_{1}=6.00069867 \times 10^{-3}$

$\mathrm{B} 2=0.231792344$

B3 $=2.00179144 \times 10^{-2}$

$\mathrm{B} 4=1.01046945$

B5 $=1.03560653 \times 10^{2}$

and $\lambda$ is the wavelength measured in $\mu \mathrm{m}$.

\section{IV.RESULTS \& DISCUSSIONS}

Figure 3 shows the refractive indices of Silica and Borosilicate materials that are calculated from the Sellmeier's equation as discussed in section III. As we can observe in Figure 3 refractive index of Silica is decreasing in the range 1.4495 to 1.4413 whereas Borosilicate is decreasing in the range 1.5062 to 1.4974 with increase in the wavelength.

Figure 4 illustrates the effective refractive indices of Silica and Borosilicate crown glass as their core materials. The influence of varying the core material is studied. It is observed that refractive index of Silica is less than Borosilicate crown glass. It is clearly obvious that the refractive indices of both materials decreasing with increase in wavelength. The effective mode index of Silica decreasing in the range 1.45 to 1.44, and of Borosilicate crown glass is 1.51 to 1.507 as a function of wavelength from $1.1 \mu \mathrm{m}$ to $1.80 \mu \mathrm{m}$.

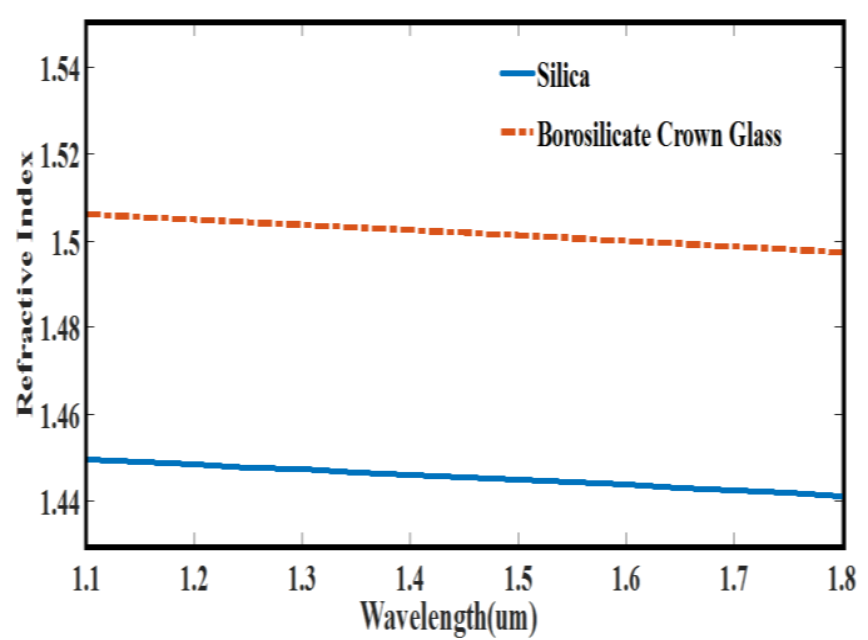

Fig. (3). Refractive indices of Silica and Borosilicate Crown glass with respect to the wavelength.

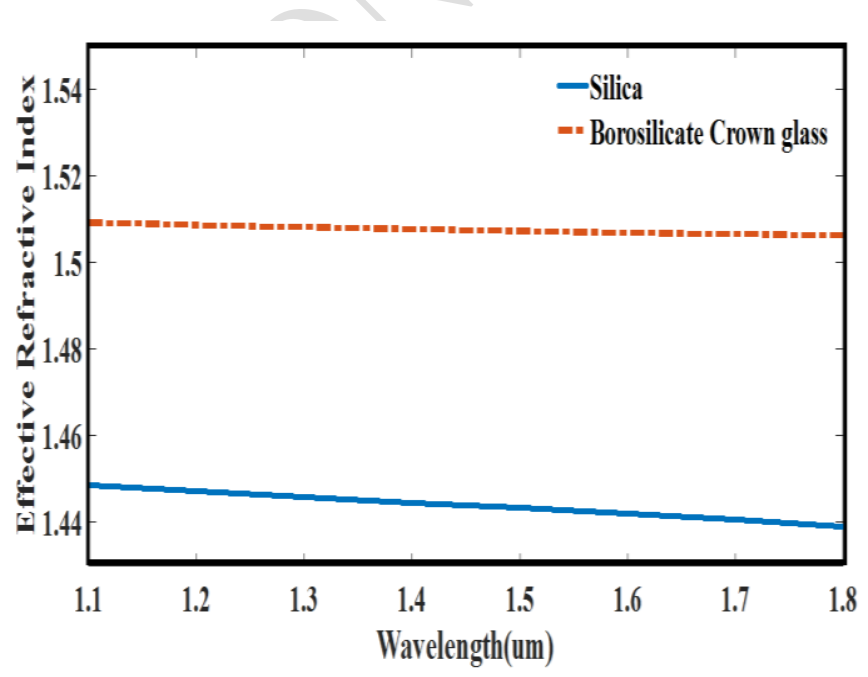

Fig. (4). Effective refractive indices of proposed Borosilicate crown glass PCF \& Silica PCF

Figure 5 demonstrates the comparison of chromatic dispersion of similar PCF with different core materials. By using the effective mode index (real part) chromatic dispersion is calculated. In Figure 5, wavelength under the range of $1.1 \mu \mathrm{m}$ to $1.8 \mu \mathrm{m}$. It shows that the dispersion characteristics of Silica PCF are nearly zero in a wide wavelength range. Thus, it is noticed that dispersion value of silica PCF is varying from $7.15 \mathrm{ps} / \mathrm{nm}-\mathrm{km}$ to $3.98 \mathrm{ps} / \mathrm{nm}-\mathrm{km}$ in the wavelength range between $1.35 \mu \mathrm{m}$ to $1.70 \mu \mathrm{m}$, which is low and flattened dispersion profile, so wavelength division multiplexing (WDM) can be applied to increase the capacity of communication channel. 


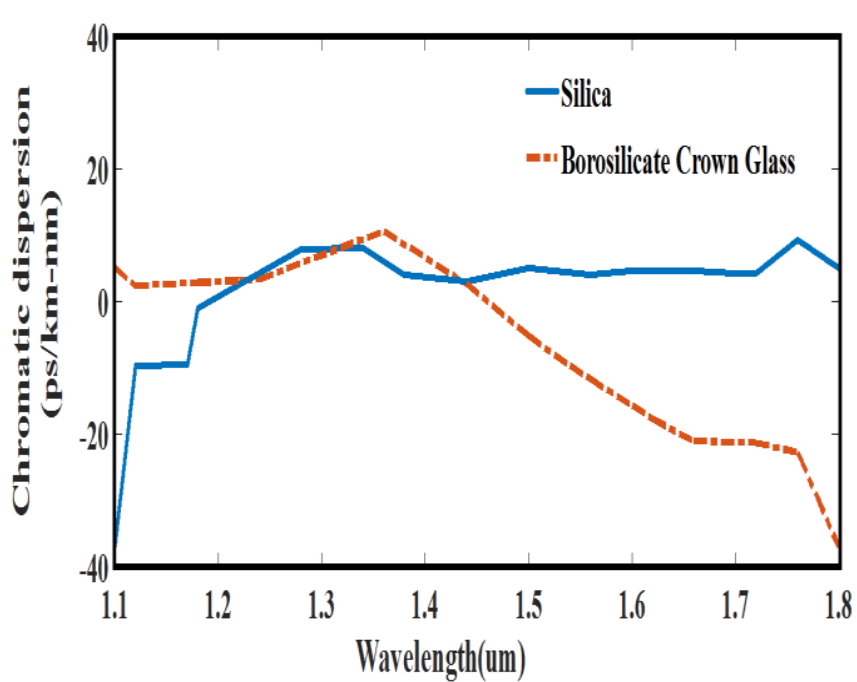

Fig. (5). Comparison of chromatic dispersion of proposed Borosilicate crown glass PCF \& Silica PCF

In contrast, the chromatic dispersion curve of Borosilicate crown glass offers negative dispersion in same wavelength range, which can be used as DCF. Hence, observe that the Borosilicate crown glass PCF provides negative dispersion from $9.75 \mathrm{ps} / \mathrm{nm}-\mathrm{km}$ to $-21 \mathrm{ps} / \mathrm{nm}-\mathrm{km}$ from $1.35 \mu \mathrm{m}$ to $1.70 \mu \mathrm{m}$ as clearly shown in Table 1 .

Table 1: Dispersion observation of Silica and Borosilicate Crown glass materials at different wavelengths

\begin{tabular}{|l|c|c|}
\hline \multirow{2}{*}{$\begin{array}{l}\text { Wavelength } \\
\boldsymbol{\mu m})\end{array}$} & \multicolumn{2}{|c|}{$\begin{array}{c}\text { Dispersion } \\
\text { (ps/nm-Km) }\end{array}$} \\
\cline { 2 - 3 } & $\begin{array}{l}\text { Silica } \\
\text { material }\end{array}$ & $\begin{array}{l}\text { Borosilicate } \\
\text { Crown Glass } \\
\text { material }\end{array}$ \\
\hline $\mathbf{1 . 1 0}$ & -36.4 & 5.34 \\
\hline $\mathbf{1 . 1 5}$ & -9.94 & 2.17 \\
\hline $\mathbf{1 . 2 0}$ & 0.811 & 2.85 \\
\hline $\mathbf{1 . 2 5}$ & 5.45 & 3.53 \\
\hline $\mathbf{1 . 3 0}$ & 8.17 & 6.92 \\
\hline $\mathbf{1 . 3 5}$ & 7.15 & 9.75 \\
\hline $\mathbf{1 . 4 0}$ & 3.64 & 6.92 \\
\hline $\mathbf{1 . 4 5}$ & 3.53 & 1.49 \\
\hline $\mathbf{1 . 5 0}$ & 5.00 & -5.53 \\
\hline $\mathbf{1 . 5 5}$ & 4.21 & -10.2 \\
\hline $\mathbf{1 . 6 0}$ & 4.55 & -15.7 \\
\hline $\mathbf{1 . 6 5}$ & 4.89 & -20.5 \\
\hline $\mathbf{1 . 7 0}$ & 3.98 & -21.6 \\
\hline $\mathbf{1 . 7 5}$ & 7.94 & -22.7 \\
\hline $\mathbf{1 . 8 0}$ & 5.00 & -37.0 \\
\hline
\end{tabular}

Furthermore, Dispersion is interlinked with the effective mode index as clearly defined in equation (2) that it is the second derivative of effective refractive index. Thus we got the change in curves evidence is figure 4 and effective refractive index depends on refractive index.

Simulation results of confinement loss, of both PCFs with respect to wavelength are presented in Figure 6. It shows that in both fibers, confinement loss increases with increase in wavelength, whereas by comparing both fibers, confinement loss of Borosilicate crown glass PCF exhibits better confinement loss characteristics than the Silica PCF.

The confinement loss of Silica is increasing from 0.0086 $\mathrm{dB} / \mathrm{km}$ to $0.0210 \mathrm{~dB} / \mathrm{km}$ from $1.1 \mu \mathrm{m}$ to $1.80 \mu \mathrm{m}$, and that of Borosilicate crown glass fiber from $0.00820 \mathrm{~dB} / \mathrm{km}$ to 0.02 $\mathrm{dB} / \mathrm{km}$. Hence, we observed that Borosilicate crown glass fiber produces low confinement loss.

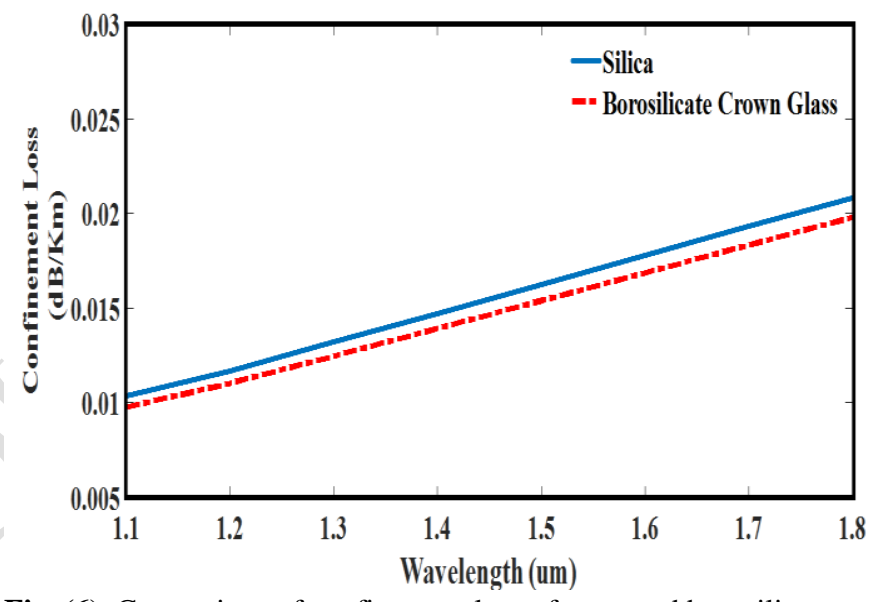

Fig. (6). Comparison of confinement loss of proposed borosilicate crown glass PCF \& silica PCF

The influence on dispersion by altering the diameter of three outer circular air hole rings by using silica core is studied by taking $\mathrm{d}=0.7 \mu \mathrm{m}, 1.0 \mu \mathrm{m}$ and $1.3 \mu \mathrm{m}$ and pitch $\Lambda=2.3 \mu \mathrm{m}$, while ellipticity of major axis of inner two rings is $\mathrm{a}=0.4 \mu \mathrm{m}$ and minor axis $\mathrm{b}=0.1 \mu \mathrm{m}$.

The changes in chromatic dispersion with respect to wavelengths in between $1.1 \mu \mathrm{m}$ and $1.8 \mu \mathrm{m}$ is presented in Figure 7. It also shows that by increasing the diameter of rings of outer air holes that is $\mathrm{d}=1.3 \mu \mathrm{m}, 1.6 \mu \mathrm{m}$ and $1.9 \mu \mathrm{m}$, chromatic dispersion also increases.

On the other hand, the influence of dispersion is also investigated, by altering the diameter of outer air holes circular rings using Borosilicate crown glass core and two inner elliptical rings with major axis $\mathrm{a}=0.4 \mu \mathrm{m}$ and minor axis $b=0.1 \mu \mathrm{m}$ as shown in figure 8 .

We have taken initial values pitch $\Lambda=2.3 \mu \mathrm{m}$, total number of rings $\mathrm{Nr}=5$ and the diameter of three outer circular air hole rings $\mathrm{d}=0.7 \mu \mathrm{m}, 1.0 \mu \mathrm{m}$ and $1.3 \mu \mathrm{m}$.

Figure 8 illustrates that by increasing the diameter of outer circular rings of borosilicate crown glass PCF, chromatic dispersion also increases. 


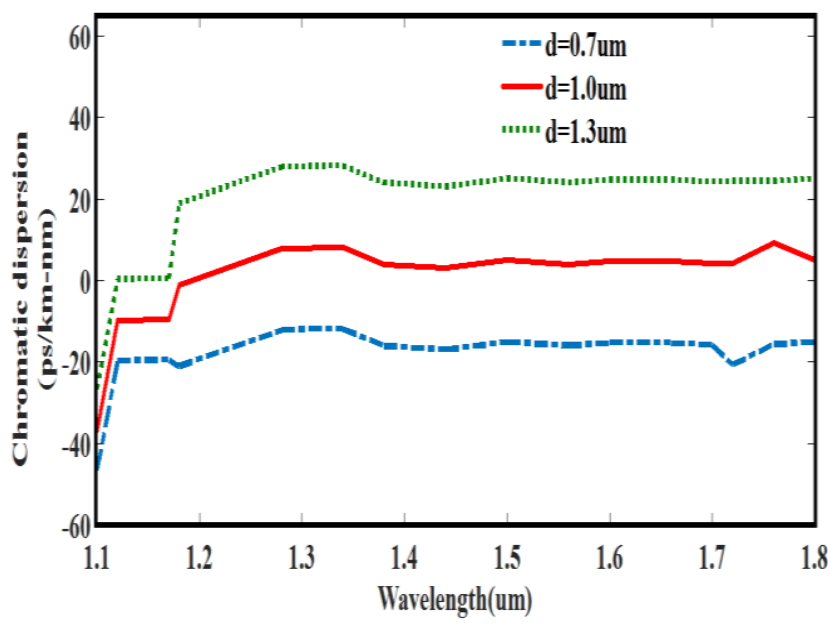

Fig. (7). Variation in chromatic dispersion of silica core PCF with wavelengths for $\mathrm{a}=0.4 \mu \mathrm{m}, \mathrm{b}=0.1 \mu \mathrm{m}, \mathrm{Nr}=5$ and $\Lambda=2.3 \mu \mathrm{m}$

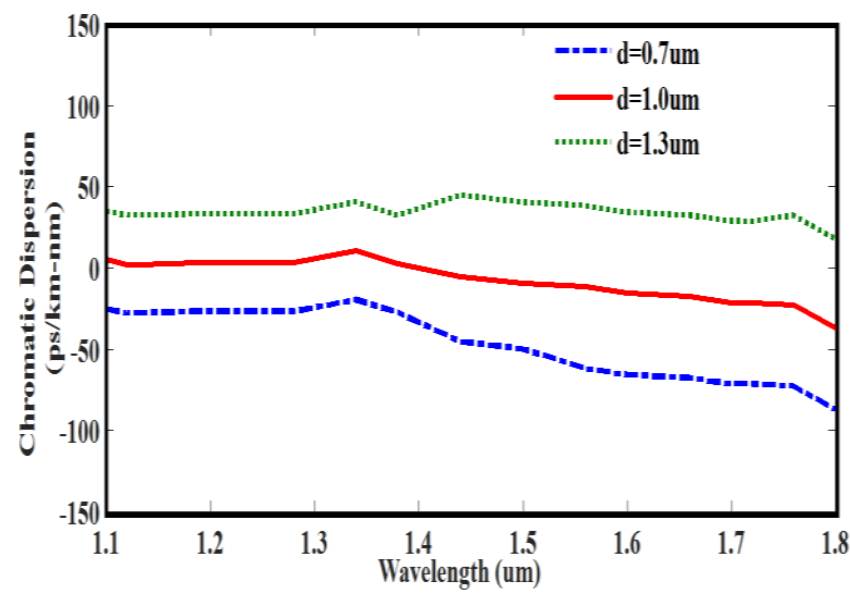

Fig. (8). Variation of chromatic dispersion of Borosilicate crown glass core PCF with wavelength for $\mathrm{a}=0.4 \mu \mathrm{m}, \mathrm{b}=0.1 \mu \mathrm{m}, \mathrm{Nr}=5$ and $\Lambda=2.3 \mu \mathrm{m}$

\section{V.CONCLUSION}

In order to achieve low flattened chromatic dispersion and low confinement loss at wide wavelength, we tried to work on it. Thus, in this research we have manifested a new design of PCF having above mentioned parameters and that is achieved by adjusting the geometry of air holes, its dimensions and pitch.

In terms of chromatic dispersion and confinement loss, we finalized that both proposed fibers exhibits remarkable performances. Silica PCF has nearly zero and favorable dispersion band in wide wavelength range, which can offer suitable optical communication, while Borosilicate crown glass fiber provides very low confinement loss with large negative dispersion as shown in Table 1 . So, we can conclude that our suggested design can be practically implemented in future wideband optical communication.

\section{REFERENCES}

[1] Ian Poole. Optical Fiber Communication [Online]. Available:https://www.electronicsnotes.com/articles/connectivity /fibre-optics/optical-fibre-telecommunications-basics.php [Accessed: $3^{\text {rd }}$ March 2020].

[2] S. Olyaee, M. Sadeghi and F. Taghipour, "Design of Low-Dispersion Fractal Photonic Crystal Fiber," International Journal of Optics \& Photonics, vol. 6, no. 1, 2012.

[3] Masayoshi Horita.(2000).Fiber Optics communication [Online].Available:https://www.fiberlabs.com/glossary/aboutoptical-communication-band/ [Accessed: 3rd march 2020.

[4] M.R Hasan, M. S. Anower and M.I.Hasan, "Polarization maintaining highly nonlinear photonic crystal fiber with closely lying two zero dispersion wavelengths," Opt. Eng., vol.55, no. 5, pp: 056107, May 2016. DOI:10.1117/1.oe.55.5.056107

[5] Partha Sona Maji, Partha Roy Chaudhuri, "A new design of ultraflattened near-zero dispersion PCF using selectivity liquid infiltration," arXiv:1412.7846, 2014.

[6] Sabrina Abedin, Avijit Hira and Sayed Mohammad Tadvin. "Novel Venus Photonic Crystal Fiber Structure with Low Loss over $\mathrm{S}+\mathrm{C}+\mathrm{L}+\mathrm{U}$ wavelength bands and large negative dispersion." In preceedings of $20^{\text {th }}$ International conference of Computer and Information Technology (ICCIT), 22-24 December, 2017. DOI: $10.1109 /$ ICCITECHN.2017.8281811

[7] A.A Nair, S. Sudheer and M. Jayaraju, "Analysis of Optical Characteristics for Photonic Crystal fiber at small core Diameters, International Jouranal of Engineering and Advanced Technology (IJEAT), vol. 3, issue-4, 2014.

[8] S.K. Singh, D. Singh and P. Mahto, "Tailoring of Flattened Dispersion in Triangular-Lattice Photonic Crystal Fiber, " International Journal of Distributed and Parallel Systems, vol. 2, p:127, 2011.

[9] Fiber Optics Handbook: Fiber, Devices, and Systems for Optical Communications, Chap.13, Mc Graw-Hill 2002, M. Bass and E.W.V Stryland.

[10] Stepniewski, G., Klimczak, M., Bookey, H., Siwicki, B., Pysz, D., Stepien, R., Buczynski, R. (2014), " Broadband supercontinuum generation in normal dispersion all-solid photonic crystal fiber pumped near $1300 \mathrm{~nm}$, " Laser Physics Letters, 11(5), 055103. DOI:10.1088/1612-2011/11/5/055103

[11] L.Cherbi, "Modeling of two rings photonic Crystal Fiber with scalar element method," J.Optoelectron. Adv. Mater. 15 (2013), no.11-12, 1385-1391.

[12] Poletti, F., Finazzi, V., Monro, T. M., Broderick, N. G. R., Tse, V., \& Richardson, D. J. (2005), "Inverse design and fabrication tolerances of ultra-flattened dispersion holey fibers," Optics Express, vol.13. no.10, 3728 . DOI: $10.1364 /$ opex.13.003728

[13] Ferhat, M. L., Cherbi, L., \& Haddouche, I. (2018), "Supercontinuum generation in silica photonic crystal fiber at 1.3 $\mu \mathrm{m}$ and $1.65 \mu \mathrm{m}$ wavelengths for optical coherence tomography," Optik, 152, 106-115. DOI:10.1016/j.ijleo.2017.09.111

[14] Jay Prakash Vijay and Md. Sabir, "Low Flattened Dispersion Hexagonal Photonic Crystal Fiber with Low Confinement Loss," International Journal of Emerging Technology and Advanced Engineering, 2008 Certified Journal, vol. 3, Issue 1, Jan 2013.

[15] Archana Mahur and Yogendra Kumar Katiyar, "Flattened Dispersion in Square Lattice Photonic Crystal Fiber of Borosillicate Material with Square \& Circular Air Holes, " International Journal of Advanced Engineering Research \& Science (IJAERS), vol.1, Issue-1, June 2014. 
[16] Z.L Liu et al., "Characteristics of a large negative dispersion and low confinement losses PCF," Semicond. Optoelectron 2008.

[17] Saitoh, K., Koshiba, M., Hasegawa, T., \& Sasaoka, E. (2003), "Chromatic dispersion control in photonic crystal fibers: Application to ultra-flattened dispersion," Optics Express, 11(8), 843.

DOI:10.1364/oe.11.000843

[18] Tzong-Lin Wu, \& Chia-Hsin Chao. (2005), "A novel ultraflattened dispersion photonic Crystal fiber," IEEE Photonics $\begin{array}{lll}\text { Technology } \quad \text { Letters, } & \text { 67-69. }\end{array}$ DOI:10.1109/lpt.2004.837475

[19] Chiang, J.-S., \& Wu, T.-L. (2006), "Analysis of propagation characteristics for an octagonal photonic crystal fiber (O-PCF)," Optics Communications, 258(2), 170-176. DOI:10.1016/j.optcom.2005.08.008

[20] Florous, N., Saitoh, K., \& Koshiba, M. (2006), "The role of artificial defects for engineering large effective mode area, flat chromatic dispersion, and low leakage losses in photonic crystal fibers: Towards high speed reconfigurable transmission platforms," Optics $\quad$ Express, 14(2), 901. DOI:10.1364/opex.14.000901

[21] Paul, B. K., Golam Moctader, M., Ahmed, K., \& Abdul Khalek, M. (2018), " Nanoscale GaP strips based photonic crystal fiber with high nonlinearity and high numerical aperture for laser applications," Results in Physics, 10, 374-378. DOI:10.1016/j.rinp.2018.06.033

[22] Monfared, Y. E., Liang, C., Khosravi, R., Kacerovska, B., \& Yang, S. (2019), "Selectively toluene-filled photonic crystal fiber Sagnac interferometer with high sensitivity for temperature sensing applications," Results in Physics, 13, 102297. DOI:10.1016/j.rinp.2019.102297

[23] Monfared, Y. E., \& Ponomarenko, S. A. (2019), "Extremely nonlinear carbon-disulfide-filled photonic crystal fiber with controllable dispersion," Optical Materials, 88, 406411. DOI:10.1016/j.optmat.2018.12.010

[24] Monfared, Y. E., \& Ponomarenko, S. A. (2016), "Slow light generation via stimulated Brillouin scattering in liquid-filled photonic crystal fibers," Optik - International Journal for Light and Electron Optics, 127(15), 5800-5805. DOI:10.1016/j.ijleo.2016.04.017

[25] H. Ademgil and S. Haxha, "Highly Birefringent Photonic Crystal Fiber with Ultralow Chromatic Dispersion and Low Confinement Losses,” J. Lightwave Techonol.26 (2008), 441-448.

[26] Md. Mamunur Rashid, Md. Shamim Anower, Md. Rabiul-Hasan and Nuzat Tabassum. "Hexagonal Shaped Core Dodecagonal PCF with High Birefringence and Nonlinear Coefficient." In Preceedings of the International Conference on Electrical, Computer and Communication Engineering (ECCE), Feb 2017, Bangladesh.

DOI: 10.1109/ECACE.2017.7912946

[27] Shafaq Mustafa, Muhammad Imran.Aslam and Irfan Ahmed. "Analysis of Electromagnetic Wave Propagation through Photonic Crystal Fibers." In Preceedings of the International Conference on Advanced Materials and Process Engineering, 1415 Dec 2015.

[28] Berenger, J.-P. (1994). A perfectly matched layer for the absorption of electromagnetic waves. Journal of Computational Physics, 114(2), 185-200. DOI:10.1006/jcph.1994.1159

[29] Gautam Prabhakar, Akshit Peer, Ajeet Kumar and Vipul Rastogi, "Finite element analysis of solid-core Photonic crystal fiber," IEEE

DOI: $10.1109 /$ SCES.2012.6199068
[30] Arjun Singh Dhakar and Yogendra Kumar Katiyar. "Highly Negative Dispersion in honeycomb Photonic Crystal Fiber of Borosilicate Material with Circular Air Holes.” In Preceedings of International Journal of Engineering, Management \&Sciences (IJEMS). ISSN-2348-3733, vol.1, Issue-12, December 2014.

[31] Sellmeier equation [Online]. Available: https://en.wikipedia.org/wiki/Sellmeier_equation [Accessed: 19th November 2019]. 